\title{
MATERIAIS DIDÁTICOS DE PORTUGUÊS DO BRASIL PARA ESTRANGEIROS
}

\section{Liliana Gottheim*}

Durante muito tempo, até o início dos anos 80 , autores de programas de ensino de línguas, dividindo-os em seus diversos aspectos - gramaticais, funcionais, lexicais, situacionais, topicais - propuseram, em suas obras, o mínimo necessário a saber para se aprender a falar uma língua estrangeira: gramática propriamente dita, vocabulário, noções e funções comunicativas (Wilkins, 1976), dentre os múltiplos elementos de língua a serem aprendidos.

A partir desse referencial teórico, cabia, aos alunos, dar organização aos elementos da língua que aprendiam, fragmentada, quando ocorressem os momentos de uso lingüístico. Evidências apontam, entretanto, que o ensino tão somente das formas parece não garantir o conhecimento de uso comunicativo (Widdowson, 1991), porque as inúmeras e diminutas peças de uma língua aprendida apresentam variados desdobramentos em seu encaixe. Para serem combinadas em situação de uso, são necessários outros conhecimentos para ajustar as partes, especialmente o das regras socioculturais.

Esses planejamentos eram fáceis de serem concretizados até por professores com modesto treinamento ou até pouco conhecedores da língua-alvo, pois propunham um professor imediatista, aplicador de decisões conteudísticas e metodológicas, tomadas previamente sobre um ensino generalizado, ministrado de forma homogênea

- Antes conhecida como Liliana STERNFELD. Prof ${ }^{\mathrm{a}}$. da Faculdade de Tecnologia HebraicoBrasileira Renascença; Mestre em Lingüística Aplicada - UNICAMP. 
a grupos de alunos diferentes. Os exercícios ou práticas rotinizantes (mnemônicos) formulados por autores e professores faziam prever a seqüência da aula, limitando a atuação pessoal dos professores ao mero cumprimento desses procedimentos.

Pouco espaço havia nesse ensino para o exercício da capacidade criativa do professor e de alunos, ao contrário do que se propõe atualmente, ou seja, da percepção sensível do professor, fazendo acontecer o melhor para sua classe (senso de plausibilidade, segundo Prabhu, 1987), gerando crescimento pessoal e humano dos participantes da sala de aula.

Na última década, as premissas teóricas veiculadas acerca do planejamento de cursos e acerca da atribuição de papéis a professores e alunos foram sendo modificadas com os ensinamentos obtidos nos métodos de pesquisa em Lingüística Aplicada, ensinamentos que obrigaram o professor a refletir e a questionar a própria prática. Dessa forma, os programas passam agora pelo crivo de validação e de adequação do professor-pesquisador, especialista na prática de sala da aula.

$\mathrm{Na}$ atualidade, professores de línguas procuram incluir, num programa de ensino, elementos nascidos da teoria (modelo de proficiência comunicativa), na tentativa de validar e adequar o que se chamaria de construto comunicativo. $\mathrm{O}$ esforço de profissionais da área de ensino de português, língua estrangeira, no último decênio, direciona-se ao desafio de operacionalizar, em um programa, um sistema integrado das habilidades lingüísticas, usando duas, três ou quatro habilidades no desenvolvimento de uma tarefa. Objetiva-se, ainda, desenvolver no aluno um sistema ampliado de competências (competência gramatical, sociolingüística e estratégica, Canale \& Swain, 1980, e discursiva, Canale, 1983) e um sistema holístico de comunicação.

Enquanto alongam-se discussões que buscam maior entendimento teórico, materiais de português para estrangeiros, que evidenciam essa tendência (programas de processo, Breen, 1984, 1987), vêm sendo elaborados e aplicados no Brasil, ainda com timidez,. especialmente os referentes à língua e às culturas do Brasil e tarefas. Materiais divulgados com brevidade, em publicações acadêmicas, tentativas não suficientemente amadurecidas para uma publicação de porte (Zilles, 1999), têm apresentado resultados e interpretações reveladoras (manifestações metodológicas) dos princípios teóricos da complexa abordagem comunicativa. Conversas com profissionais da área de ensino de língua estrangeira lembram que o nome abordagem comunicativa apareceu (no Brasil) como um avião enorme, ou seja, aterrissou ruidosamente como um grande avião, causando na atuação de professores um impacto paralisante. Embora seus verdadeiros pressupostos não sejam tão complexos depois de estudados, 
o nome apareceu com força máxima para contrapor-se às abordagens gramaticais até então vigentes.

A SIPLE (Sociedade Internacional de Português Língua-Estrangeira), em sua reunião anual, indica perspectivas promissoras a um investimento continuado na construção de novos materiais. Contudo, esses movimentos são lentos, restringem-se a pequenos grupos que trabalham por sua conta, e que terminam, muitas vezes, por não publicar seus resultados.

Outras iniciativas, nesse sentido, também firmam-se em consequiência da elaboração do primeiro exame nacional de proficiência comunicativa em português-língua estrangeira do Brasil, CELPE-BRÁS (Certificado de Língua Portuguesa para Estrangeiros), aplicado pela primeira vez em 1998. Dentre os benefícios desse exame, destaque-se, o denominado efeito retroativo que ele tem na segunda fase do Modelo de Operação Global do Ensino de Línguas (Almeida Filho, 1993: 19), mais especificamente, a fase referente à questão da produção de materiais. Tal fato já tinha sido mencionado por Scaramucci em 1995. Uma vez que este exame será aplicado pela segunda vez, em 1999, avaliadores do projeto começam a sentir a necessidade de produzir materiais comunicativos preparatórios.

Outras iniciativas de aplicação de testes de avaliação de proficiência comunicativa de português para estrangeiros ( $\mathrm{PE}$, doravante) desenvolvem-se na Universidade de São Paulo, por meio de convênio, tanto em São Paulo, como no exterior. À medida que dados de ambos os projetos puderem ir sendo repassados à comunidade acadêmica, ela poderá beneficiar-se deles, para a construção de novos materiais elaborados a partir da prática das tarefas. Tarefas têm marcado esses tipos de planejamentos por promover a oportunidade de linguagem e atitudes ajustadas espontaneamente ao interlocutor e/ou ao propósito comunicativo. Construir e organizar tarefas, prever suas possibilidades interativas é uma modalidade com a qual ainda não estamos familiarizados na área de PE. Faltam estudos e a questão ainda não foi dominada. Isso parece causar dificuldades na construção de novos materiais de PE, que objetivem o sentido de comunicação, repensando a forma.

As várias definições do termo tarefa, existentes na literatura (Xavier, 1999), assinalam seu escopo cognitivo e pragmático (social/interacional). O cognitivo, levando-se em conta o papel de fomentador do raciocínio e o pragmático, visando a desenvolver processos de aquisição de competências nos alunos. A tarefa, como expediente gerador de interação entre aluno-texto, professor-aluno, alunos-alunos, no trabalho em sala de aula, detém, nesse conjunto de relações, o potencial para desenvolver em alunos e professores tais capacidades. 
Amostras de linguagem imprevistas, aleatórias, motivadas pessoalmente pelos participantes de aula, podem ser incorporadas e realimentar o enunciado inicial de uma tarefa preparada e redigida pelo professor. Essas amostras podem ser apontadas, dentre outras, como um inesperado divertido, uma piada, ironia, analogia inteligente, como inesperado heurístico, quando o aluno busca explicação, clarificação, checagem, como inesperado catártico ou narrativo, toda vez que o aluno conta úm caso, uma experiência, e deseja compartilhar idéias, fantasias, necessitando reelaborar pensamentos (Sternfeld, 1996).

Todos sabemos que são nesses momentos comunicativos que emergem os problemas de aprendizagem. Professores de línguas têm realizado tarefas conscientizadoras e momentos de sistematização gramatical em suas aulas para tomada de consciência pelos alunos de suas falhas estruturais, mas este tema reclama discussão.

O potencial humano de criação e a diversidade cultural no Brasil, o interesse e a elevada formação na compreensão de questões educacionais de que dispomos, seriam fatores enriquecedores na área de construção de materiais, se tivéssemos mais extensa troca de informações sobre experiências realizadas com tarefas em salas de aula de português para estrangeiros. A situação engendrada pelas tarefas é rica enquanto comunicação e apresenta muitas possibilidades de retomadas teóricas a partir de subsídios gerados na prática, fazendo com que o escopo final de um curso, mais do que nunca, seja, em sua versão concreta, o resultado da recriação conjunta de professores e de alunos, a partir do programa inicial. Essa recriação, com a co-autoria conteudística de insumo suplementar provinda dos alunos, poderá ser considerada e aproveitada em novos cursos, polindo, cortando, e atualizando tarefas, imprimindo versatilidade ao movimento proposto no programa inicial.

A aplicação desses planejamentos tem assinalado a necessidade de fazê-los acompanhados por sistemas de avaliação do próprio processo em andamento, ao mesmo tempo em que exige professores com alto nível de competência lingüística e de aplicação. A escassez de materiais, destinados à nova visão de ensinar e de aprender línguas, no momento em que é necessário integrar ao material outras fontes de insumo, especialmente oriundas dos alunos, tem sobrecarregado, na difícil busca de recursos, professores atuantes e decididos a modificar suas práticas arraigadas no ensino de estruturas. A aplicação dessas abordagens contemporâneas também tem sido difícil para determinadas culturas nacionais e a divulgação dessas experiências estrangeiras é relevante para a área. 
Ao final do texto, trago, a título de exemplo, a reprodução de um roteiro de tarefas de um curso de PE, que elaborei sobre o filme Central do Brasil, numa tentativa de mostrar, em planejamento concreto, como a situação engendrada pelas tarefas é rica enquanto comunicação, oferecendo ao aluno oportunidade para desenvolver fluência, vivência intercultural e outras experiências lingüísticas.

Os objetivos inerentes às tarefas aqui desenvolvidas foram primordialmente oferecer aos alunos a oportunidade de expressão e diálogo com outras pessoas na língua estrangeira. A pergunta que se coloca é, como dar conta dos níveis de precisão/ correção da língua, na medida em que surgem problemas na produção do aluno, combinando essas questões em um único programa, considerando-se, principalmente, a regra, que é o tempo curto de permanência do aluno estrangeiro no programa? A visão dessas dificuldades não esmorece, pois percebemos que a instrumentação que vimos emergir nas novas pesquisas, nas novas experiências, traz-nos a certeza de que as poderemos vir a compreender com maior clareza.

FILME CENTRAL DO BRASIL

ROTEIRO DE MATERIAL DE ENSINO DE BASE CULTURAL DE UM CURSO DE PE (elaboração a partir do vídeo, do livro, do site na internet, de jornais e de revistas informativas)

(1) Preliminar: os alunos terem assistido ao filme Central do Brasil. Diretor Walter Salles; pré-estréia no Brasil, março de 1998.

Objetivo: sensibilização cultural.

(2) Pergunta formulada pela professora para a sala:

O filme é marcado por várias cenas impressionantes. Reporte uma que the tocou bastante (interação: professor-alunos/alunos-professor).

Objetivos: reconstituir cenas do filme; compartilhar idéias; manifestar curiosidades interculturais; fazer surgir vocabulário específico, culturalmente marcado (ex. romeiro, romaria, peregrinação etc.). 
(3) Dez fotos compiladas sobre cenas do filme e distribuídas para os alunos.

(a) Encontre uma ordem cronológica para as fotos, numerando-as, seguindo a história do filme (interação: alunos-alunos em pequenos grupos).

(b) A seguir escolha 2 fotos que sejam significativas para você e escreva um parágrafo que lembre o acontecido na foto (interação: aluno-texto).

Objetivos: reconstituir a história do filme, esclarecendo eventuais cenas mal compreendidas; fazer produção escrita.

(4) Resumo publicado em revista e sinopse extraída da internet entregues aos alunos.

(a) Leia os dois resumos adiante, silenciosamente, compare-os, e discuta com colegas, qual seria escolhido como o melhor resumo produzido para um leitor que não viu o filme (interação: aluno-texto; alunos-alunos em pequenos grupos). Justifiquem sua resposta (interação: professor-alunos/alunos-professor).

(b) Em seguida leiam as perguntas formuladas abaixo opinando sobre elas e tentando chegar a um consenso (interação: alunos-alunos em pequenos grupos).

1) Você achou o filme comovente? Caso sua resposta seja afirmativa explique por que ele está comovendo as pessoas em todo o mundo.

2) A problemática desse filme tem caráter universal ou é apenas um problema nacional? O que você acha? Explique.

3) Por que a autora diz, no primeiro resumo, que "Central do Brasil tem a cara do País"?

4) O que você viu, ouviu falar ou conhece, a fundo, sobre as imagens místicas e religiosas que povoam o Nordeste, mencionado no primeiro resumo? 
Objetivos: ler, comparar e comentar resumos; aprender vocabulário novo; compartilhar idéias; promover discussão intercultural.

(5) Preliminar: Leitura de parte do texto do jornal OESP, 27 mar. 98, intitulado: "Central do Brasil mostra como nasce um país".

(a) Faça para a próxima aula uma leitura silenciosa do texto adiante e procure entender o sentido das palavras grifadas (interação: aluno-texto).

(b) Prepare respostas por escrito para as perguntas abaixo e venha preparado na próxima aula para uma discussão coletiva (interação: aluno-texto).

1) Quais são esses valores perdidos, essa ética que Dora e Josué buscam resgatar com tanta determinação?

2) O texto define Dora como figura espertalhona, malandra, trambiqueira, mas tudo é perdoado pela simpatia que desperta. Como você define essa figura malandra na cultura do Brasil?

3) Qual a relação que se estabelece entre o pai ausente e o pai da Nação (governo), ou seja, a busca pelo pai que deserdou o menino e a busca pelo pai da Nação que deserdou seus filhos?

4) O que o autor quer dizer com sertão periférico? Que relação se estabelece com viver na periferia da sociedade?

5) Segundo o título do artigo, por que "Central do Brasil mostra como nasce um país"? Qual a crítica que está embutida no título? (interação: professor-alunos/alunos-professor)

Objetivos: ler cuidadosamente, aprender vocabulário novo; fazer produção escrita; compartilhar idéias; promover discussão intercultural. 
(6) Fotos compiladas sobre os personagens principais e entregues aos alunos.

(a) Observe os nomes dos personagens principais cotejados aos nomes verdadeiros dos atores que os representam. Escolha dois desses personagens para descrevê-los fisicamente e psicologicamente, assim como sua maneira de vestir ao longo do filme (interação: aluno-texto).

(b) Depois disso, selecionando-se na classe um personagem de cada vez, todos podem escutar a descrição feita e lida por um aluno para tal personagem, compartilhando na classe diferentes leituras e definições (interação: alunos-alunos).

(c) Comparem ainda, no final da atividade, essas definições elaboradas individualmente com os comentários da professora sobre cada personagem (extraído da internet - distribuido para os alunos ou projetado em transparência), dicutindo-os coletivamente (interação: professor-alunos/alunosprofessor).

Objetivos: desenvolver vocabulário e maior compreensão sobre a cultura brasileira; desenvolver conhecimento pessoal entre os alunos; compartilhar idéias.

(7) Preliminar: Leitura de parte do texto do jornal OESP, 24 abr. 98, intitulado: "Atuação de coadjuvantes marca Central do Brasil".

(a) Faça para a próxima aula uma leitura silenciosa do texto adiante e escreva de um a dois parágrafos sobre um dos personagens secundários (interação: aluno-texto).

(b) Divida com os colegas as informações contidas em cada um de seus parágrafos e as dificuldades de vocabulário levantadas do texto (interação: alunos-alunos).

(c) Em discussão coletiva comente sobre o que a leitura lhe esclareceu elou enriqueceu (interação: professor-alunos/alunos-professor). 
Objetivos: Ler cuidadosamente; desenvolver língua em uso e produção escrita; ampliar o universo cultural sobre o Brasil.

(8) Leiam a questão e discutam-na em pequenos grupos elegendo um secretário para fazer anotações dos pontos levantados pelo grupo.

(...) “A viagem de Josué em direção ao seu passado inverte o eixo de migração norte-sul e permite que o menino redefina a sua própria estória. Ele é acompanhado na sua busca por uma velha mulher que se tornou insensível, cínica, mas que também busca a segunda chance que a libertará de sua existência mesquinha." (trecho extraído da internet - seção: "Depoimentos").

A viagem no filme não é apenas a grande viagem do Rio de Janeiro ao Nordeste de ônibus. Existem as pequenas viagens que vão modificando os personagens.

(a) ida e volta para casa no trem da Central;

(b) a viagem com o caminhoneiro;

(c) a viagem no caminhão "pau de arara" com os romeiros;

(d) o percurso a pé no meio das velas da romaria e na capela;

(e) a viagem a pé pelas cidadezinhas do nordeste, onde tiram fotografia juntos, onde compram um vestido novo; Dora acordando no colo do menino, após desfalecer, a procura pela casa do pai de Josué indo bater de porta em porta.

Responda:

1) Quais pessoas, lugares ou atitudes tiveram papel fundamental para que esse aprendizado ocorresse? (interação: alunos-alunos)

Objetivos: sensibilização cultural. ampliação da percepção cultural sobre o Brasil.

(9) A partir do filme e das idéias até aqui discutidas, que curiosidade, quanto ao Brasil ou a sociedade em geral, acentuou-se? Surgiu, segundo você, algum tema a pesquisar melhor? 


\section{Bibliografia}

ALMEIDA FILHO, J.C. P. (1993) Dimensões comunicativas no ensino de línguas. Campinas: Pontes.

BREEN, M. P. (1984) Process Syllabuses for the language classroom. In: BRUMFIT, C. J. (ed.). General English Syllabus Design. Oxford: Pergamon Press and the British Council. Contemporary paradigms in syllabus design. Part I and II. Language Teaching 20, v. 20, n. 2, p. 81-93, abr. 1987 e n. 3, p. 156-173, jul. 1987.

CANALE, M. e SWAIN, M. (1980) Theoretical bases of communicative approaches to language teaching and testing. Applied Linguistics 1, n. 2, p. 1-47.

CANALE, M. (1983) From communicative competence to communicative language pedagogy. In: RICHARDS, J. e SCHMIDT, R. (orgs.). Language and Communication. New York: Longman, p. 2-27.

PRABHU, N. S. (1983) Procedural Syllabuses. Singapore; SEAMEO Regional Language Centre, 18th Regional Seminar, p. 1-6, 1983. . (1987) Second Language Pedagogy. Oxford: Oxford University Press.

SCARAMUCCI, M. V. R. (1995) "O projeto CELPE-BRÁS no âmbito do Mercosul: contribuições para uma definição de proficiência comunicativa”. In: ALMEIDA FILHO, J. C. P. (org.). Português para estrangeiros interface com o Espanhol. Campinas: Pontes, p. 77-90.

STERNFELD, (GOTTHEIM) L. (1996) Aprender Português língua-estrangeira em ambiente de estudos sobre o Brasil: a produção de um material. Dissertação de Mestrado, UNICAMP.

XAVIER, R. P. (1999) A aprendizagem em um programa temático de língua estrangeira (inglês) baseado em tarefas em contextos de $5^{a}$ série do ensino fundanental. Dissertação de Doutorado, UNICAMP.

WILKINS, D. A. (1976) Notional Syllabuses. Oxford: Oxford University Press.

ZILLES, A. M. S. (1999) Curso de conversação de Português: relato de experiência. In: CUNHA, M. J. e SANTOS, P. Ensino e pesquisa em Português para estrangeiros. Brasília: Edunb, p. 71-85. 
Linha d'Água, n. especial, p. 91-107, jan. 2000.

\section{FOTOS DE CENAS DO FILME}
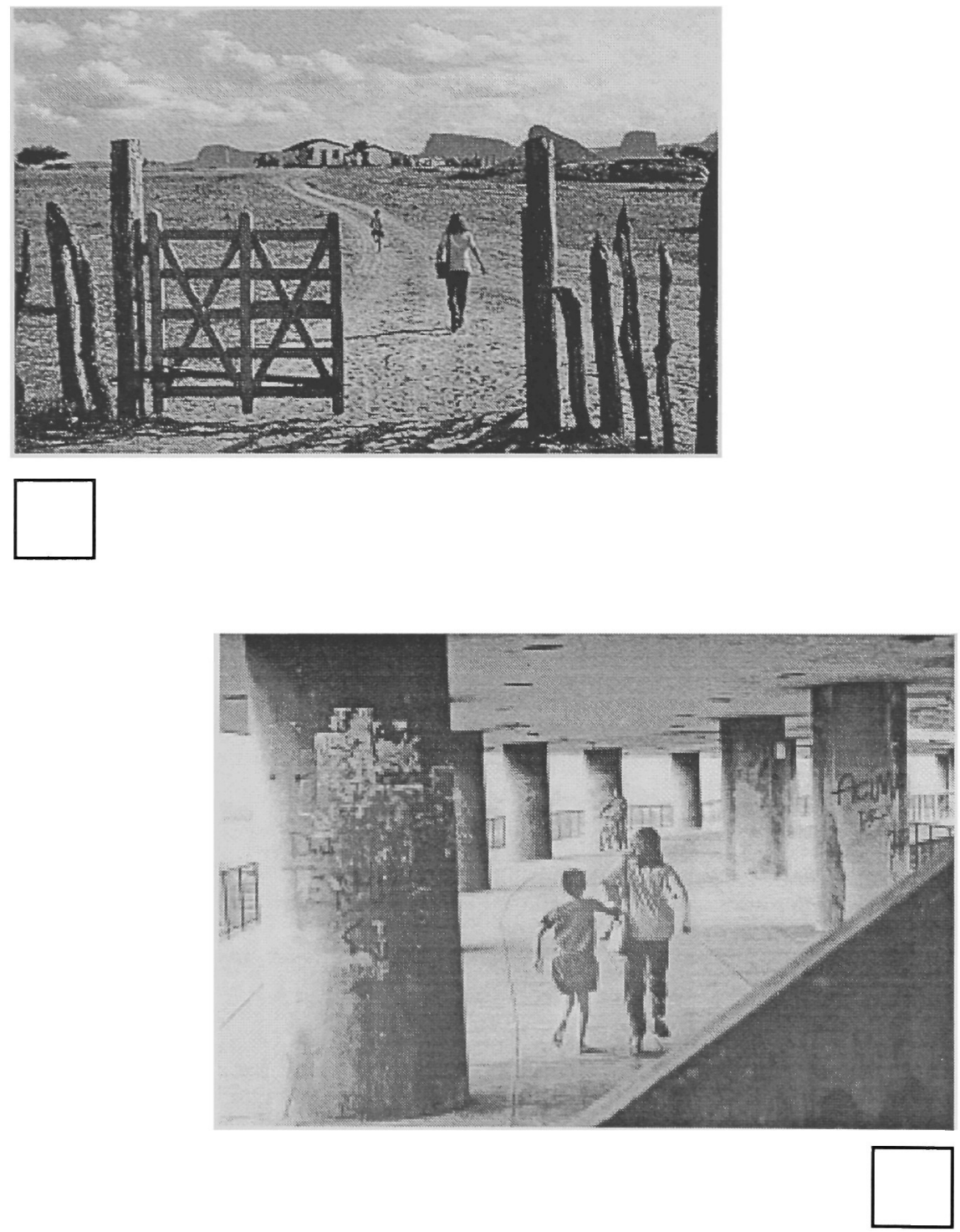
GOTTHEIM, Liliana. Materiais didáticos de português do Brasil para estrangeiros.
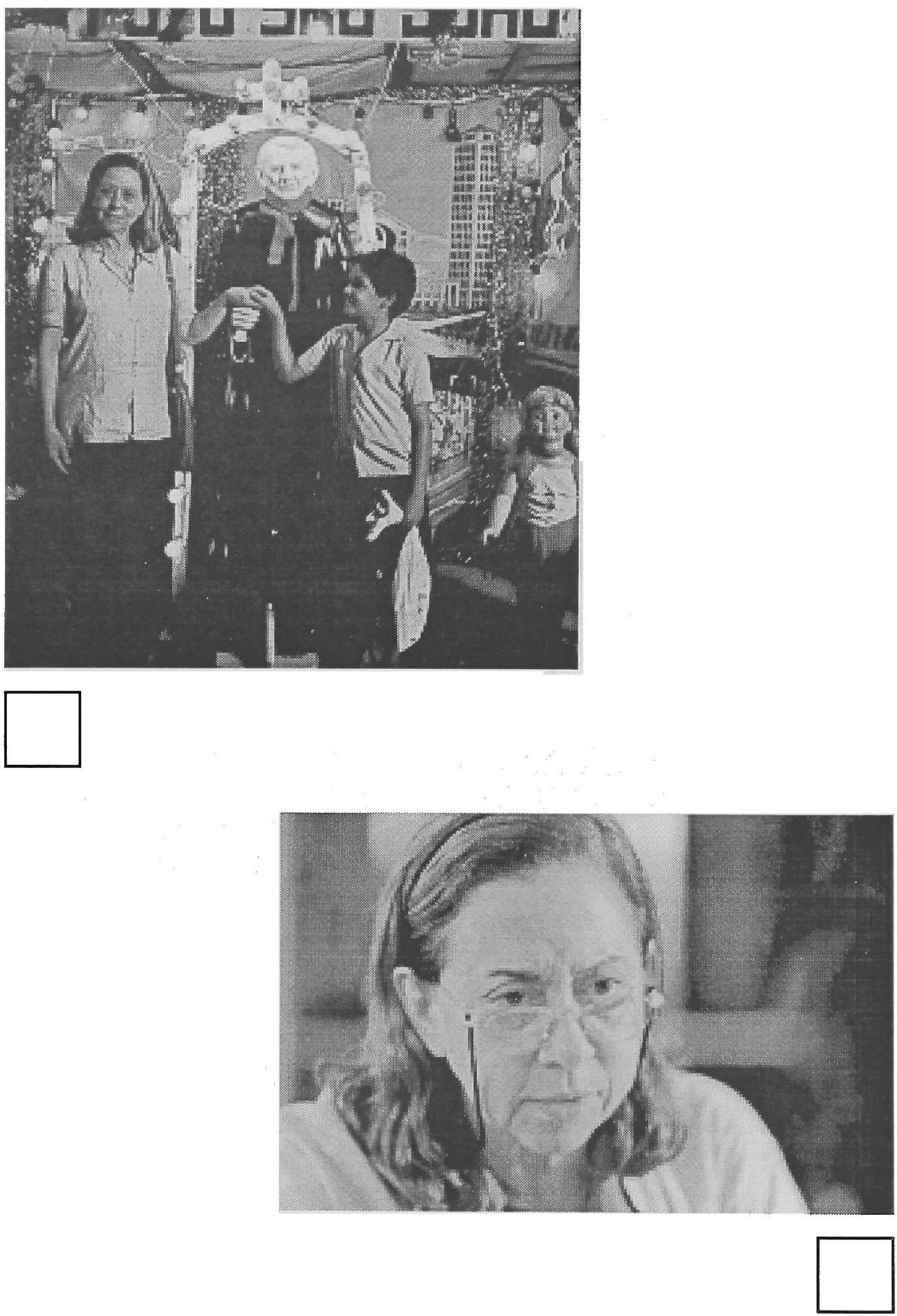
Linha d'Água, n. especial, p. 91-107, jan. 2000.
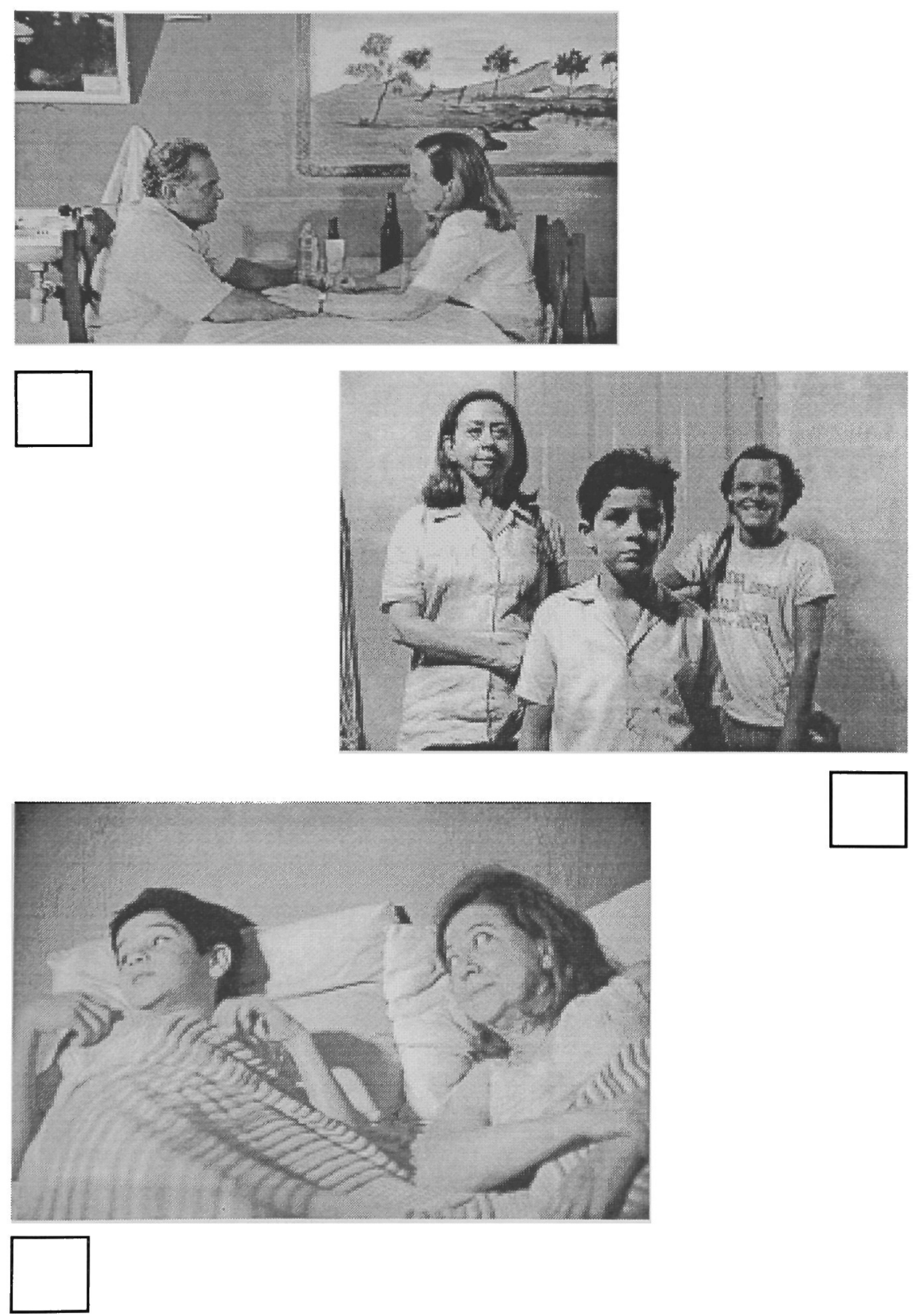
GOTTHEIM, Liliana. Materiais didáticos de português do Brasil para estrangeiros.
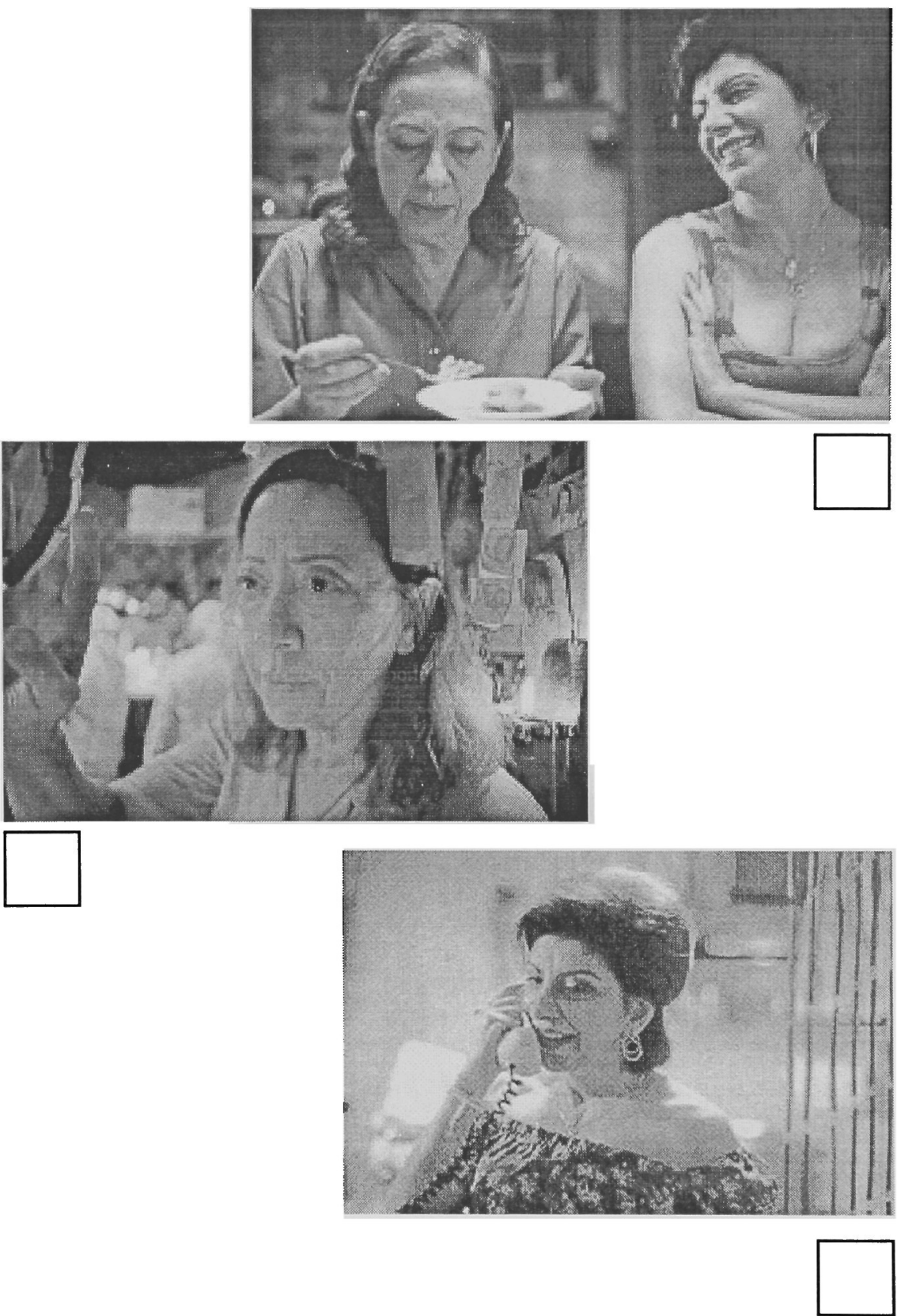


\section{RESUMOS DO FILME CENTRAI DO BRASII}

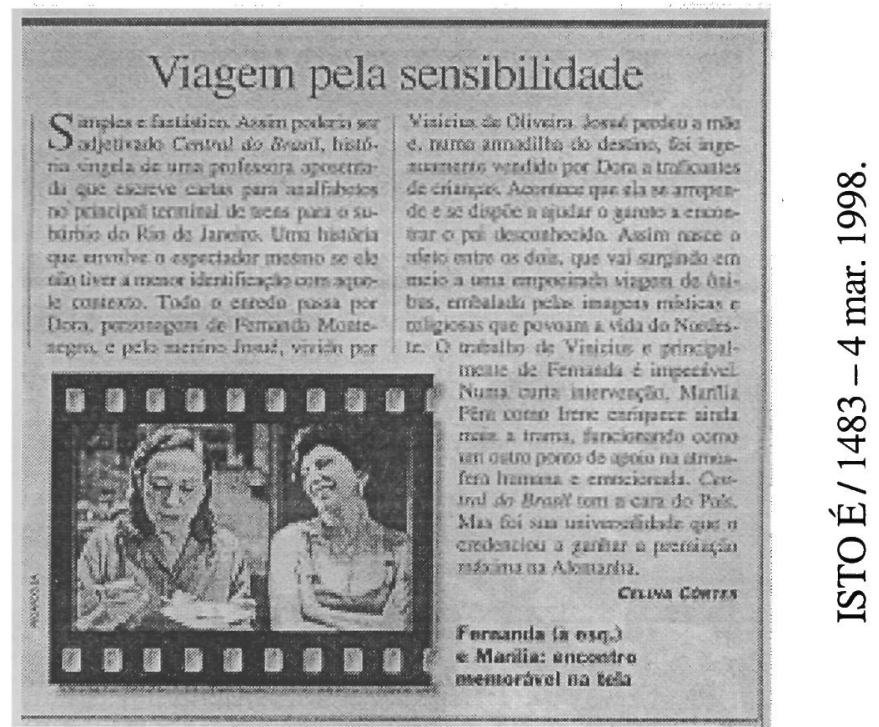

Dora (Fernanda Montenegro) escreve cartas para analfabetos na central do brasil. Nos relatos que ela ouve e transcreve, surge um Brasil desconhecido e fascinante, um verdadeiro panorama da população migrante, que tenta manter os laços com os parentes do passado.

Uma das clientes de Dora é Ana, que vem escrever uma carta com seu filho, Josué (Vinícius de oliveira), um garoto de nove anos, que sonha encontrar o pai que nunca conheceu. Na saída da estação, ana é atropelada e Josué fica abandonado. Mesmo a contragosto, dora acaba acolhendo o menino e envolvendo-se com ele. Termina por levar Josué para o interior do nordeste, à procura do pai. À medida que vão entrando país aden- tro, estes dois personagens, tão diferentes, vão se aproximando... começa então uma viagem fascinante ao coração do Brasil, à procura do pai desaparecido, e uma viagem profundamente emotiva ao coração de cada um dos personagens do filme.

Sinopse do filme Central do Brasil

(extraída da internet)

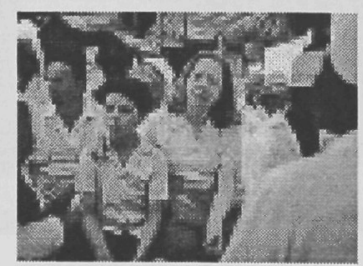




\section{PERSONAGENS PRINCIPAIS}

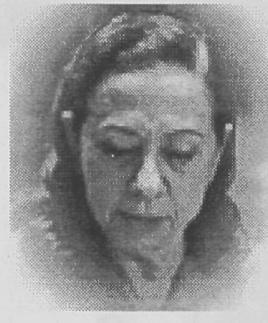

Fernanda Montenegro DORA

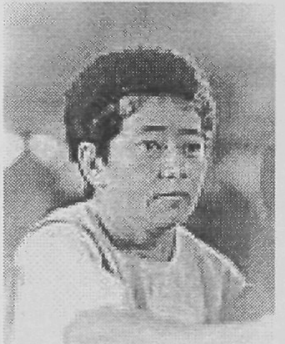

Sônia Lira

ANA

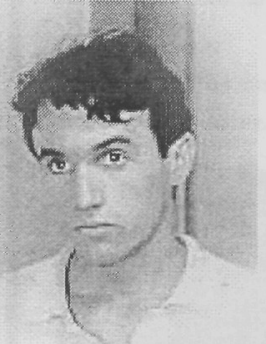

Caio Junqueira MOISÉS

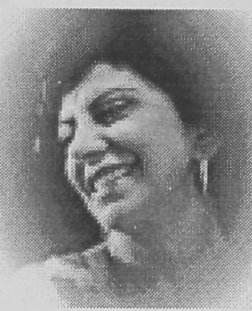

Marília Pêra IRENE

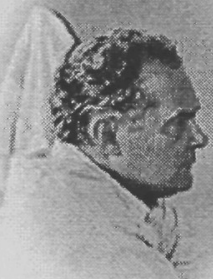

Othon Bastos

CEZAR

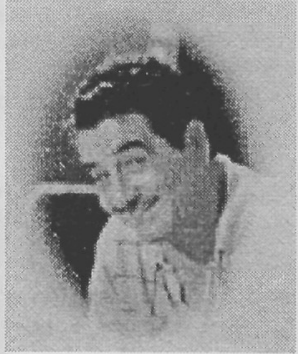

Otávio Augusto PEDRÃO

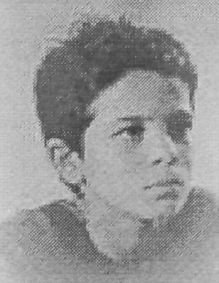

Vinícius de

Oliveira JOSUÉ

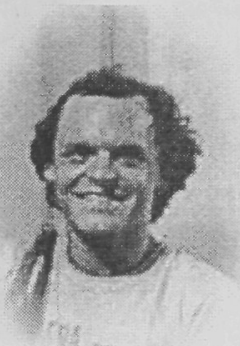

Matheus Nachtergaele ISAÍAS

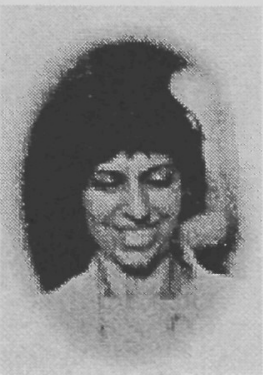

Stella Freitas YOLANDA 


\section{'Central do Brasil' mostra como nasce um país}

Oncontro de dois miseráveis, que descobrem a ética e a esperança, é o tema do filme dirigido por walter Salles e premiado no Festival de Berlim, que tem pré estréia amanhã em oito cinemas de São Paulo.

Antônio Goncalves Filho

(...) o humanismo de Walter Salles não é um humanismo escolástico. Ele não transforma en metáforas seus dois personagens - uma mulher que escreve cartas para analfabetos na Central do Brasil e um garoto sem pai. São pessoas de came e osso, dois zumbis sociais, que encontram a vida juntos e forjam uma ética após vagar pelo deserto, o sertão periférico. Fora do centro, portanto, onde a ética já morreu. Reside aí uma imprecisão terminológica. Não morreu. Foi assassinada a porretadas por poderosos que desprezan tudo aquilo que não é espelho.

Ao contrário dessa gente, os pobres que ditam cartas para Dora (Fernanda Montenegro) na Central do Brasil sabem que a única possibilidade de escapar do círculo infemal dos predadores é a união. Ao perder a mãe, atropelada por un ônibus, a garoto Josué (Vinícius de Oliveira) aproxima-se daquela que decide $o$ destino de outros miseráveis. Sozinha e abandonada, Dora já cruzou a linha da ética há muito tempo. Seleciona as cartas que deven ou não ser enviadas a seus desti- natários. A carta ditada pela mãe de Josué a seu companheiro Jesus nunca chegaria a seu destino, não fosse a detenninação do deserdado en procurar o pai. E o que faz Dora? Troca o garoto por uma televisão, ao entregar a "mercadoria" a traficantes de crianças.

Arrependida, volta atrás e foge com Josué para o sertão atrás de Jesus, o pai. Em linhas gerais Central do Brasil é uma denúncia vigorosa sobre o genocídio praticado pelos burgueses contra os miseráveis. Josué corre o risco de ter seus órgãos vitais retirados para transplantes. Dora vê na desgraça do garoto o espelho de seu abandono. Aí começa a via da redencão. 0 deserto purificador representado pelo sertão significa não apenas o reencontro com o Brasil esquecido, mas a recuperação de valores a partir do zero. É lá que ambos vão construir uma ética para sobreviver.

o maior mérito do filme é justamente esse, o de falar do marco zero da ética sem cair num discurso frio, intelectual. Salles usa as referências de sua cultura cinematográfica - do Wim Wenders de Alice nas Cidades ao Angelopoulos de Paisagem na Neblina - , e faz seu filme mais pessoal. Central do Brasil é um sincero e emocionante filme de autor, curiosamente um homem rico que desceu ao mundo dos miseráveis para redescobrir a esperança. 


\section{Atuação de coadjuvantes marca 'Central do Brasil'}

\section{Beth Néspoli}

(...) vale destacar a ação de três coadjuvantes justamente pela grande dimensão que eles emprestam a pequenos papéis: Marília Pêra, Othon Bastos e Matheus Nachtergaele, não por mera coincidência, três protagonistas nos palcos. Marília vive Irene, a amiga de Dora; Bastos, o caminhoneiro que dá carona a Dora e o menino num pequeno trecho da viagem e Nachtergaele surge nos minutos finais do filme, como irmão do garoto.

"São papéis extremamente pequenos no filme, servem de escada para os atores principais", diz Marília. No entanto, apesar da participação episódica, o público sai com a certeza de que a vida de cada um deles daria outro filme, igualmente emocionante. "Waltinho não criou um filme pirotécnico, mas, sim, um humano; ele é delicado no tratamento, gosta do ator e confia nele", diz Nachtergaele.

Com um elenco desses, pode. Assim como o cineasta sueco Ingmar Bergman, Walter salles pode dar-se ao luxo de manter a câmera, sem nenhum movimento, no rosto de qualquer um desses três atores e obter um cena plena de significado e emoção. É o que ocorre, por exemplo, quando o ator Mateus Nachtergaele ouve de Fernanda Montenegro a leitura de uma carta. Sem uma palavra, ele leva o público às lágrimas. "Nesse momento o personagem faz uma descoberta muito im- portante". diz Nachtergaele. No filme ele não diz que descoberta é essa. Apenas sente. E o público sente com ele.

Decepção no olhar - é também unicamente no olhar que o ator othon Bastos revela a decepção e conflito interior de seu caminhoneiro com um atitude inesperada de Dora. Novamente a câmera de Walter Salles foca o rosto do ator. Não há palavras. Ele não move um único músculo sequer e no entanto a densidade de sua expressão vale por mil palavras. Em seguida ele sai de cena e o espectador não precisa de qualquer explicação para sua retirada. Tudo estava dito.

o mesmo misto de desconfiança e decepção estampa-se no rosto de Marília ao intuir o grau de degradação atingido pela amiga Dora. Atriz de rara consciência profissional, diz ter resistido antes de aceitar o papel. Lembra que pequenas participações de grandes atores é prática recorrente no cinema mundial.

Porém ressalva que seria preciso valorizar essas participações também no aspecto financeiro. "No Brasil, a gente faz as coisas de forma diferente, mas acho que seria preciso pedir aos patrocinadores uma remuneração justa para esse tipo de participação". Apesar da queixa nem de longe se arrepende de ter cedido aos insistentes apelos do diretor. "Sinto-me honrada por estar nesse filme."
Marilia Pêra mostra sua sensibilidade na construção de Irene
Othon Bastos cria belo solo e imprime credibilidade a papel
Nachtergaele dá o clima de emoção com poucas falas 